Issues in Information Systems

Volume 18, Issue 4, pp. 70-90, 2017

\title{
FACTORS AFFECTING TRUST IN SOCIAL COMMERCE: A STRUCTURAL EQUATION MODEL
}

\author{
C. Christopher Lee, Central Connecticut State University, christopher.lee@ccsu.edu \\ Young Sik Cho, Jackson State University, young_sik.cho@jsums.edu \\ B. Benjamin Bae, California State University, Bakersfield, bbae@csub.edu
}

\begin{abstract}
This study attempted to investigate what factors significantly affect trust in social commerce. The authors proposed five factors including social influences, customer attitudes/biases/past experiences, reputation of business, reputation of peers, and transactional security. The authors employed three models including multiple regression model, logistic regression model and structural equation model. Sample data was collected from a survey questionnaire. The study found that peer reputation and transaction security significantly affected consumer trust when using social commerce to purchase goods online. Social influence, customer attitude, and business reputation had mixed results. When segmenting by gender, the trust of women was found to be significantly impacted by social influence, customer attitude, and peer reputation, while peer reputation and transaction security significantly impacted men's trust.
\end{abstract}

Keywords: e-commerce, social commerce, consumer trust, online transactions

\section{INTRODUCTION}

The electronic commerce (e-commerce) topic has been highly stressed in recent years and it continues to be an important topic as the phenomenon continues to grow and expand in business. Within e-commerce social media has proved to be a powerful promotion tool for businesses that are attempting to expand sales online. Harnessing the power of online social media to leverage competitive advantage is becoming more important to businesses around the world and will, without a doubt, continue into the future.

Through the initial research the authors have determined that trust between businesses and consumers is very important and it seems to be a key factor in building positive social commerce (s-commerce) relationships which in turn help increase sales (Beyari, \& Abareshi, 2016). The authors would like to further research the topic of trust in s-commerce by identifying factors that create trust between businesses and consumers in the online environment. The authors identified many factors that help create or limit trust in s-commerce and have determined that the most important factors are social influence (Hajli, 2014; Beyari, \& Abareshi, 2016; Shin, 2013; Shanmugam, 2016; Fairweather, 2004; Chen, 2015), customer attitudes toward products or services (Hsiao, 2010; Beyari \& Abareshi, 2016; Shin, 2013; Bai, Yao, \& Dou, 2015; Talat, Azar, \& Yousaf, 2013; Hajli, 2013; Shanmugam, Sun, Amindi, Khani, \&, Khani, 2016; Mutz, 2009; Craig, 2004; Chen, 2003; Han \& Windsor, 2011), reputation of business and of peer reviewers (Beyari and Abareshi, Braynov \& Sandholm, Han and Winsor, 2011; Hsiano, 2010), and transaction security (Beyari and Abareshi, 2016; Hsiano, 2010; Lee, 2015). The authors believe these factors have a significant impact on s-commerce and need to be considered when attempting to build trustworthy relationships with their online customers. Trust oftentimes gets used as a factor within the models and it usually has a high predictability associated with it; however, no studies have been directed toward the factors that impact a consumer's level of trust in s-commerce. This study aims to discover how the factors of social influence, reputation of a business or website, validity of peer reviewers, a consumer's prior experience, and transaction security impact trust in s-commerce activities.

The purpose of this study is to identify the effect the defined factors have on trust within the context of the s-commerce phenomenon. The survey of past studies shows a lack of research on this topic; therefore, this research project seeks to fill in the gap in the literature. The authors will use a questionnaire that caters to the factors the authors defined from the research that impact trust within s-commerce. The authors used a seven-point a Likert scale with one representing a strongly disagree opinion, four being neutral and seven corresponding to a strongly agree opinion. The authors will conduct multiple regression analysis, logistic regression analysis, and structural equation model to identify 


\section{Issues in Information Systems \\ Volume 18, Issue 4, pp. 70-90, 2017}

the relationships between the defined variables and how they impact trust and draw conclusions that will help business using s-commerce businesses attempt to establish trust with their customers.

This paper consists of a literature review followed by methodology and statistical results of the study. Lastly the results are discussed and the authors apply the finding to managerial decisions within the context of s-commerce in the conclusion.

\section{LITERATURE REVIEW}

Electronic commerce (e-commerce) is the buying and selling of goods and services, or the transmitting of funds or data, over an electronic network, primarily the internet (Rushton, Croucher, and Baker, 2017). The internet gave us the ability to obtain information and create connections otherwise inaccessible. These connections created a platform for a new means of commercial exchange or electronic commerce (e-commerce). With the dawn of social media, what used to be called e-commerce has morphed into what the authors generally refer today as social commerce or scommerce. "Social commerce ... is a new form of electronic commerce that involves using social media, an online media that supports social interaction and user contributions, to assist in the online buying and selling of products and services" (Shen and Eder 2011). In other words s-commerce can be defined as online transactions that are influenced or brought upon by the interaction of businesses and their consumers on an electronic social level (Shen and Eder 2011). There have been many studies conducted on s-commerce and the authors have identified a common theme of trust and the contribution to future studies is finding out how it impacts the success of online transactions as defined in s-commerce.

Hajli (2014) provides an s-commerce adoption model that is based on the relationship between customers who use the internet and social platforms. The research indicates that customers are able to better know the products and services because they can use social networking platforms to both share information and access information from others. In their investigation of what impact trust has on market efficiency and bilateral contracts, Braynov \& Sandholm (2002) found that markets where the parties can be trusted to a degree can be perceived as complete trustworthiness which creates an efficient market.

S-commerce gains its social aspects from user generated ratings and content as well as sharing of information and advice about products. Shin (2013) explains that investing in trust building and communicating trust is worthwhile, as it is essential for attracting and retaining customers. Perceived trust positively influences s-commerce behavior (Shin 2013). With this premise, Shin advises that consumer attitudes toward websites, brands or products can affect trust and cites an example from a survey in Bailey (2010), showing that $25 \%$ of consumers who are connected to brands on Facebook did so to receive discounts. Shin's study contributes to the literature on Theory of Planned Behavior research by highlighting that trust and social support can influence behavioral intentions through attitude. Shin cites research from Buttner \& Goritz (2008) and Wu \& Tsang (2008) explaining that when knowledgeable friends recommend specific products, the potential customer can jump straight to the purchase. Users look for the presence of positive cues about a site's general trustworthiness, as well as for the absence of negative cues and these cues can influence a customer's impression of trustworthiness and increase or decrease their desire to interact.

Liang, Ho, Li, \& Turban (2011-12) determined that social networking/media has an impact with regards to ecommerce. The authors used dimensions of social support, relationship quality and website quality to identify which, if any, have a significant impact on a user's intention to continuously use a website and intention to share and receive commercial information. Bai, Yao, \& Dou (2015) identifies variables that affect consumer purchase intent. They develop and validate a conceptual model identifying social factors like social support, seller uncertainty and product uncertainty and their influence on online consumer behavior. After performing regression analysis, (Bai et al., 2015) found that social support, the use of a third-party, seller's morality/services and product quality affects the intent to purchase as defined by uncertainty or level of trust.

Lee, Park, \& Han (2011) investigates the effects of two types of online customer reviews also referred to as OCRs (online customer reviews) and OEAs (OCR's Embedded in Advertisements) on consumers' purchase intention from an informational influence perspective as well as the effects of OCRs from a credibility perspective. The results show that Electronic Word-of-Mouth (which OCRs are a type) are more influenced by trust in online shopping malls than 


\section{Issues in Information Systems \\ Volume 18, Issue 4, pp. 70-90, 2017}

OEAs (Lee et al., 2011). Talat, Azar, \& Yousaf (2013) explores how s-commerce and trust affect consumer value, as well as the relationship between perceived risk and perceived value on trust. It also investigates the connection between affective influence, Word-of-Mouth, advertising influence, purchasing experience, and viral reach on scommerce. The two most significant variables in driving purchase intent proved to be trust and attitude, both of which have a positive effect on purchase intent (Talat et al., 2013).

Beyari \& Abareshi (2016) explored factors that influence consumer satisfaction in s-commerce by developing a framework using trust and social influence theories. Beyari \& Abareshi. (2016) extend Kim \& Park (2013) trust theory to define the relationship between s-commerce and trust. The study is a continuation of the s-commerce research framework that gives insight into which factors affect consumer satisfaction. Lee, Kim, Chung, \& Lee (2016) analyzed and explored factors that affect perceived customer value in group-buying and explored the influence of price on consumers' trust in social media platforms and their reputations. Results indicated that consumers' value perceptions and purchase decisions are driven by lower prices - consumers are more likely to be satisfied by the s-commerce experience when they receive low prices.

Hwang, Lee, \& Kim (2014) explored the factors that influence customers' behavioral character and purchasing behavior by examining factors such as social presence, information asymmetry, and trust. Overall, the research lends insight into consumer behavioral characteristics in s-commerce and gives potential methods for s-commerce sites to utilize in instilling trust in consumers (Hwang et al., 2014). Hajli (2013) develops a theoretical framework for scommerce/e-commerce with trust as a mediating factor. Hajli (2013) uses trust as a foundation to test the s-commerce constructs (SCCs): forums and communities, ratings and reviews, and recommendations and referrals. Trust is more important when risks are perceived to be high (Mutz 2005). The research shows that the s-commerce constructs significantly influences trust and intention to buy (Hajli 2013).

Kuo-Lun Hsiao, Xiang-Ying, Hsi-Peng, \& Yu (2010) examines two aspects of trust in s-commerce: trust in product recommendation and trust in the s-commerce site itself on the intention of purchase. The study found that increased degrees of perceived ability, integrity, and critical mass will increase consumer's perceived trust in product recommendations to make purchases and increased degrees of consumer's perceived web reputation, web quality, and institution assurance will increase the consumer's trust in the s-commerce site and the intent to purchase. Han \& Windsor (2011) examines a consumer's willingness to pay on social network sites, finding that social activities enhance user's trust and in business transactions over s-commerce. Han \& Windsor (2011) found that user's trust in s-commerce has a significant positive effect on the user's willingness to pay on the site and user's trust in other members of the s-commerce site has a significant positive effect on willingness to pay on the site.

Shi \& Chow (2015) conceptualizes that trust in s-commerce includes two dimensions, information-based trust and identification-based trust. Shi \& Chow (2015) hypothesized correctly that information-based trust and identificationbased trust in an s-commerce site is positively related to consumer trust in that company and consumers' prior experience with a company negatively moderates the relationship between information-based s-commerce trust and company trust. Lee (2015) studied trust in s-commerce with respect to information disclosure, barriers to entry, and community policing to understand how trust works in a single transaction, how information plays a role in these transactions, and lastly, how the law works within these new transactions. It was found that trust comes from the experience of others. It was found that safeguards and controls in place had a greater significance on trust than prior purchase experience (Lee 2015).

Shanmugam, Sun, Amindi, Khani, \&, Khani (2016) studied customers and if they are more likely to proceed with transactions when trust has been previously established, and/or is in existence. It was found that s-commerce leads to greater emotional and informational support. As informational and emotional support increase, trust in online community also increases. Sanghyun (2013) studied s-commerce growth in Korea. It was found that s-commerce users are likely to trust s-commerce so long as favorable environments exists (Sanghyun 2013).

Bin $\mathrm{Yu}$ (2002) looked at reputations of buyers/sellers, reputation management, and how this factors into trust. The study looks at the data through a 'referral network,' where both parties must trust one another for both to benefit. This, however, implies that the two parties must continuously interact with one another. Mutz (2009) looked at s-commerce and how a positive experience leads to social trust. The study found that individuals who have bought online in the 
past have higher trust levels than those who have not (Mutz, 2009). Mutz also found that positive e-commerce experience equals more trust and negative e-commerce experience leads to less trust.

Chen \& Shen (2015) investigates s-commerce from two different but related perspectives: social shopping and social sharing. The results of the study suggested that community commitment and users' trust toward community were the two most important factors in s-commerce. Informational support and emotional support were found to be significantly correlated to user's trust and commitment. Van Slyke, Belanger, \& Comunale (2004) hypothesize that trust is significantly correlated with consumer's intent to conduct e-commerce. The study concludes that perceptions of trust are related to intentions to shop over the web. Craig (2004) explores e-commerce and the factors that increase confidence and trust in the online shopping experience in Taiwan. The study concludes that there is no difference between males and females and online consumer trust.

Chen (2003) examines which factors cause a user to trust a website and provided a theoretical model for managers to be able to develop internet marketing strategies that develop consumer trust. Six factors in the study were identified to have a significant influence on the formation of a consumer's overall trust in a website: reputation, website characteristics, service quality, overall satisfaction, perceived risk, and education. Fairweather (2004) empirically examined the possibility that the introduction of s-commerce has had a positive impact on the development of marketing relationships through increased trust and commitment. The results of this study supported current literature on trust and commitment: e-commerce activities affect trust and commitment. All of the tested factors were found to be significantly statistically correlated to both trust and commitment.

In summary, there are many studies that focus on social influence that examine online customer testimonials, ratings and the trust in these sources and their impact on purchase decisions. Studies have considered how customer attitudes/biases and positive or negative past experiences, reviews and one's own personal values impact trust and willingness to make purchases now or in the future. Furthermore, there are many studies that examine a business' reputation and how this affects consumer trust and willingness to make online purchases. Likewise, peer reputation has been studied with respect to the recommendations, advice, feedback and support from peers in the online community. Finally, transaction security has been considered to investigate the impact of safe and private transactions on trust. However, no study was found to encompass all five variables into trust. This study aims to discover how the factors of social influence, customer attitudes/biases, reputation of a business or website, reputation of peers, and transaction security impact trust in s-commerce activities. This study thoroughly surveys past studies and seeks to fill in the gap in literature. This paper hypothesizes that social influence, customer attitudes/biases, reputation of a business or website, reputation of peers, and transaction security are all significantly related to trust in s-commerce and that each positively impacts the s-commerce experience.

\section{METHODOLOGY}

Many studies argued that social influence has a significant impact on trust in s-commerce. Chen and Shen's (2015) study suggests that community commitment and users' trust toward community were the two most important factors in s-commerce. Informational support and emotional support were found to be significantly correlated to user's trust and commitment. Shanmugam, Sun, Amindi, Khani, \&, Khani (2016) study found that s-commerce leads to greater emotional and informational support. As informational and emotional support increase, trust in online community also increases. Fairweather's (2004) study empirically examined the possibility that the introduction of s-commerce has had a positive impact on the development of marketing relationships through increased trust and commitment, his results were found to be significantly statistically correlated to both trust and commitment. Hajli (2013) study concludes that social trust improves efficiency, facilitates business expansion, and attracts more customers leading to greater sales. Therefore, this study hypothesizes that social influence has a significant relationship with trust.

\section{Hypothesis 1: Social influence is significantly related to trust in s-commerce.}

Survey questions related to this hypothesis include:

- Item 1a (Q4): Customer testimonials usually impact my decision to make a purchase.

- Item $1 \mathrm{~b}(\mathrm{Q} 6)$ : I often seek opinions of online shoppers who face similar problems as I do.

- Item 1c (Q14): I tend to trust the ratings on s-commerce websites. 
- Item 1d (Q18): I often like to talk with other online shoppers about mutual opinions and experiences.

Several studies have argued that customer attitudes, biases, and past experiences have a significant effect on trust in s-commerce. In Chen's (2003) study, six factors were identified to have a significant influence on the formation of a consumer's overall trust in a website: reputation, website characteristics, service quality, overall satisfaction, perceived risk, and education. Craig's (2004) research found that perceived risk was the most important factor in online consumer trust. Han \& Windsor (2011) found that trust in s-commerce has a significant positive effect on the user's willingness to pay on the site and user's trust in other members of the s-commerce site has a significant positive effect on willingness to pay on the site. Shanmugam, Sun, Amindi, Khani, \&, Khani (2016) studied customers and if they are more likely to proceed with transactions when trust has been previously established, and/or is in existence. A survey was created and embedded into websites like LinkedIn, Facebook, and Twitter. It was found that s-commerce leads to greater emotional and informational support. As informational and emotional support increase, trust in online community also increases. Therefore, this study hypothesizes that customer attitudes, biases, and past experiences are significantly related to trust.

\section{Hypothesis 2: Customer attitudes, biases, and past experiences are significantly related to trust in s-} commerce.

Survey questions related to this hypothesis include:

- Item 2a (Q1): I tend to benefit from reviewing feedback on social networks before making an online purchase.

- Item $2 \mathrm{~b}(\mathrm{Q} 10)$ : I typically will not make an online purchase if I have had a bad experience with the company (regardless of strong peer reviews).

- Item 2c (Q17): The social aspect of online shopping enables me to discover new products and get shopping ideas quicker.

- Item 2d (Q19): Without positive s-commerce community feedback on a product or service I will not make a purchase.

- Item 2e (Q24): My personal values impact how much trust I have in s-commerce.

Many studies have researched whether the Reputation of a business has an effect on Trust in s-commerce. Bin Yu (2002) looked at reputations of sellers, reputation management, and how this factors into trust. In s-commerce, buyers can rate seller's performances and this is important because others could then see this rating. This shows other potential customers how reliable, and/or unreliable a seller truly is. Customers look at this online information before they make purchase decisions, thus we hypothesize that business reputation has a significant impact on trust.

\section{Hypothesis 3: Reputation of business is significantly related to trust in s-commerce.}

Survey questions related to this hypothesis include:

- Item 3a (Q5): When shopping online, I believe that the company is acting in the best interest of others.

- Item 3b (Q13): I use s-commerce services for brands that I am loyal to.

- Item 3c (Q21): The general reputation of a company impacts my decision to make an online purchase from their website.

The authors hypothesized that a business reputation is correlated to trust, so using Bin Yu's (2002) study which looked at the data through a 'referral network,' where both parties must trust one another for both to benefit. The authors hypothesize that the reputation of peers is related to Trust in s-commerce.

\section{Hypothesis 4: Reputation of peers is significantly related to trust in s-commerce.}

Survey questions related to this hypothesis include:

- Item 4a (Q2): I feel that recommendations from my peers are generally reliable.

- Item $4 \mathrm{~b}(\mathrm{Q} 8)$ : I expect that the advice given by the s-commerce community is their best judgement.

- Item 4c (Q11): I get the emotional help and support I need from the s-commerce community.

- Item 4d (Q16): When shopping online, I believe that the s-commerce community is acting in the best interest of others.

- Item 4e (Q23): I generally trust the feedback about a company from those in the s-commerce community. 
Several studies have explored transactional security's impact on trust. Craig (2004) explores e-commerce and the factors that increase confidence and trust in the online shopping experience in Taiwan. The study concludes that perceived risk was the most important factor in online consumer trust; perceived online privacy was the second; thirdparty assurance seal was the third; perceived online security was the fourth. No customer is interested in having their credit card of personal information stolen, so based on these results hypothesize that transactional security is related to trust.

\section{Hypothesis 5: Transactional security is significantly related to trust in s-commerce.}

Survey questions related to this hypothesis include:

- Item 5a (Q9): S-commerce websites give me an impression that they keep my privacy information safe.

- Item 5b (Q15): Using a third party payer website (such as PayPal) makes s-commerce transactions safe.

- Item 5c (Q22): I believe s-commerce websites have my information safety in mind.

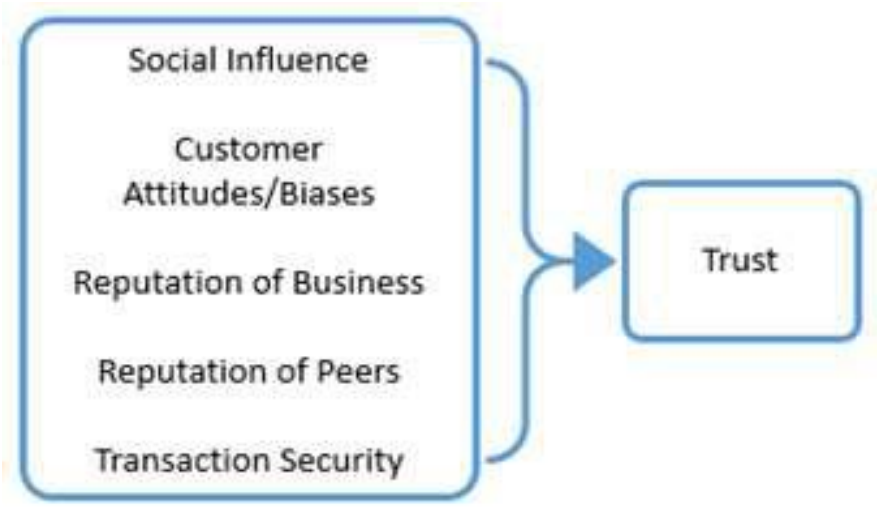

Figure 1. Research Framework

\section{Analytics Model}

This study plans to build a model that shows how different variables impact trust in s-commerce. The model in Figure 1 shows trust as being the dependent variable. The independent variables are social influence, customer attitudes/biases, reputation of business, reputation of peers, and transactions security. The research question "What affects trust in s-commerce" and the five research hypotheses would lead to the development of a self-administrated questionnaire research study, with descriptive and exploratory purposes. The design focused on quantitative methods with close-ended questions on the survey tool. A seven point Likert rating scale was used.

Survey questions related to the trust variable include:

- Item 6a (Q3): I trust online shopping websites like Amazon and eBay.

- Item $6 \mathrm{~b}(\mathrm{Q} 7)$ : I tend to use a credit/debit card to purchase products and services online.

- Item 6c (Q12): I trust the product/service information displayed on social networks.

- Item 6d (Q20): I trust social networking websites.

Social influence will increase the level of trust in s-commerce. When individuals use social networking websites in an effort to use s-commerce, they drive the hype. The more that this happens, the more relevant it becomes. This relevancy only drives/promotes s-commerce.

Positive customer attitudes will increase the level of trust while negative customer attitudes will decrease the level of trust in s-commerce. It all about service. Consumer experience is important. The authors all have opinions. When the authors share this with others, the authors paint a picture in consumers' minds. This leads to either a positive or negative opinion for consumers. 
Business or website with a positive reputation will impact trust positively and vice versa. The authors read and come up with rationales as to why certain things happen and why certain things do not. This is what leads to reputations. If the authors know that a business has a positive reputation the authors are more likely to trust it because the authors know/interpret for it to be true.

Reputable peers will influence the trust level depending on their feedback. This is important to note. The authors tend to trust our friends on social media more than a random person on an online review. This is because this platform offers more of a personal touch.

Transaction security positively influences Trust. The more secure the transaction is the more trustworthy the scommerce website will be. If the authors trust a business, the authors feel safe doing more business with in the long terms.

When it comes to Social Influence and Trust, Liang, Ho, Li, \& Turban (2011-12) determined that social networking/media has an impact with regards to e-commerce. This come in the form of having a good experience in the e-commerce platform, returning to the social networking site, then making recommendation/evaluation based on the experience. These experiences can of course be both positive and negative. Based on the results or review customer can be swayed towards or away from a product or service. This demonstrates how both social influence and customer attitudes/biases can have an impact on trust. Lee, Park, \& Han (2011) took an interesting take in that the study focused on credibility and how it impacts trust.

Shin (2013) explains that investing in trust building and communicating trust is worthwhile, as it is essential for attracting and retaining customers. This too is important in terms of how consumers react or act based on what they see/learn on these social media platforms. This particular study does a good job of showing how trust influences consumers based on customer attitudes, but also the reputation of business.

Bai, Yao, \& Dou (2015) developed a model that identified several factors like social support, seller uncertainty and product uncertainty and their influence on online consumer behavior. If consumers are reluctant to trust a website or business, they are less likely to trust/put good faith in a business transaction. Braynov \& Sandholm (2002) also talks about transaction security and how it relates trust in social commerce.

To further study the model/theory, the authors will be running various regression models. By doing this the authors will be able to pinpoint more clearly what factors and/or combinations of factors impact trust more when it comes to social commerce.

\section{Model Equations}

Variables

$$
\begin{aligned}
& \mathrm{Y}=\text { Level of Trust } \\
& \mathrm{X}_{1}=\text { Social Influence } \\
& \mathrm{X}_{2}=\text { Customer Attitude } \\
& \mathrm{X}_{3}=\text { Peer Reputation } \\
& \mathrm{X}_{4}=\text { Business Reputation } \\
& \mathrm{X}_{5}=\text { Transaction Security }
\end{aligned}
$$

\section{Regression Model}

$$
\mathrm{Y}=\text { Intercept }+\mathrm{B}_{1} \mathrm{X}_{1}+\mathrm{B}_{2} \mathrm{X}_{2}+\mathrm{B}_{3} \mathrm{X}_{3}+\mathrm{B}_{4} \mathrm{X}_{4}+\mathrm{B}_{5} \mathrm{X}_{5}
$$

\section{Logistic Regression Model}

$$
\begin{gathered}
\text { Score }(Y)=\text { Intercept }+B_{1} X_{1}+B_{2} X_{2}+B_{3} X_{3}+B_{4} X_{4}+B_{5} X_{5} \\
p=\frac{e^{Y}}{1+e^{Y}}
\end{gathered}
$$

where $\mathrm{p}=$ the probability of success $($ dependent variable $=1)$ 


\section{Issues in Information Systems}

Volume 18, Issue 4, pp. 70-90, 2017

\section{Sampling plan}

Based on the independent variables, the authors have developed several hypotheses that will be tested using a questionnaire which was created for this study specifically. In all 24 questions were created that catered to each of our six variables including Trust as the dependent variable. The authors also included 5 demographic questions that will help us in creating focused models and provide greater segmenting power for better insight. The questionnaire was distributed to local college students, employees of a few different industries, and peers within the greater Hartford, $\mathrm{CT}$ area. In all 134 surveys were collected. After analyzing the data the authors were able to use all data gathered. The authors believe that the data is sufficiently diversified and is a good random sample of the population and is valid in terms of testing the theories.

\section{RESULTS}

Table 1 shows descriptive statistics for demographic variables described in questions 25 - 29 (i.e. Education, Income, Age and Gender). The questionnaire was distributed to people in the Hartford, CT area with 134 valid samples collected. The authors were able to use all data collected to when creating the models.

Table 1. Online Purchases

\begin{tabular}{|l|r|r|}
\hline & Frequency & \multicolumn{1}{|c|}{ Percent } \\
\hline 1.0 Never & 5 & 3.7 \\
\hline 2.0 & 26 & 19.4 \\
\hline 3.0 & 16 & 11.9 \\
\hline 4.0 Sometimes & 30 & 22.4 \\
\hline 5.0 & 24 & 17.9 \\
\hline 6.0 & 15 & 11.2 \\
\hline 7.0 Always & 18 & 13.4 \\
\hline Total & 134 & 100.0 \\
\hline
\end{tabular}

There seems to be a fairly regular distribution of the frequency of Online Purchases between the two extremes of Never and Always online buyers. This means that the data is a good representation of the random sample of the population.

Table 2. Education Level

\begin{tabular}{|l|r|r|}
\hline & Frequency & \multicolumn{1}{c|}{ Percent } \\
\hline Some High School & 1 & .7 \\
\hline High School Diploma & 13 & 9.7 \\
\hline Some College & 23 & 17.2 \\
\hline 2yr College Degree & 12 & 9.0 \\
\hline 4yr College Degree & 57 & 42.5 \\
\hline Master Degree & 17 & 12.7 \\
\hline Doctoral Degree & 5 & 3.7 \\
\hline Prefer - No Response & 6 & 4.5 \\
\hline Total & 134 & 100.0 \\
\hline
\end{tabular}

As Table 2 presents, nearly $90 \%$ of our sample population has above a High School diploma with regards to education, with the majority $(\approx 59 \%)$ having a four year College Degree or higher. 
Table 3. Yearly Income

\begin{tabular}{|l|r|r|}
\hline & Frequency & \multicolumn{1}{c|}{ Percent } \\
\hline$<\$ 25,000$ & 12 & 9.0 \\
\hline$\$ 25,000-\$ 40,000$ & 17 & 12.7 \\
\hline$\$ 41,000-\$ 60,000$ & 20 & 14.9 \\
\hline$\$ 61,000-\$ 80,000$ & 28 & 20.9 \\
\hline$\$ 81,000+$ & 31 & 23.1 \\
\hline Prefer No Response & 26 & 19.4 \\
\hline Total & 134 & 100.0 \\
\hline
\end{tabular}

Table 3 reports that some $65 \%$ of respondents earn $\$ 41,000$ or more so the authors can say that they have purchasing power. However nearly a fifth of respondents preferred not to disclose their income level.

Table 4. Age

\begin{tabular}{|l|r|r|}
\hline & Frequency & \multicolumn{1}{|c|}{ Percent } \\
\hline $18-24$ & 24 & 17.9 \\
\hline $25-34$ & 38 & 28.4 \\
\hline $35-44$ & 37 & 27.6 \\
\hline $45-54$ & 12 & 9.0 \\
\hline $55+$ & 18 & 13.4 \\
\hline Prefer No Response & 5 & 3.7 \\
\hline Total & 134 & 100.0 \\
\hline
\end{tabular}

Table 4 shows that nearly $83 \%$ of the sample population is between the ages of $18-54$ and more than half of these can be classified as millennials (18-34).

Table 5. Gender

\begin{tabular}{|l|r|r|}
\hline & Frequency & \multicolumn{1}{|c|}{ Percent } \\
\hline Female & 64 & 47.8 \\
\hline Male & 68 & 50.7 \\
\hline Prefer - No Response & 2 & 1.5 \\
\hline Total & 134 & 100.0 \\
\hline
\end{tabular}

The responses between Female and Male as shown in Table 5 are nearly even with $47.8 \%$ being women and 50.7 being men. This means that the authors have a relatively unbiased sample in regard to Gender.

Table 6. Descriptive Statistics

\begin{tabular}{|l|r|r|r|r|r|}
\hline & \# of Cases & Minimum & Maximum & \multicolumn{1}{c|}{ Mean } & Std. Deviation \\
\hline Trust & 133 & 2.25 & 6.50 & 4.8365 & .87421 \\
\hline Social Influence & 133 & 1.00 & 7.00 & 4.6316 & 1.20273 \\
\hline Customer Attitude & 134 & 1.80 & 6.80 & 4.7657 & .93440 \\
\hline Peer Reputation & 134 & 1.00 & 6.20 & 4.2716 & .94683 \\
\hline Business Reputation & 134 & 1.00 & 6.67 & 4.7114 & .89442 \\
\hline Transaction Security & 133 & 1.00 & 7.00 & 4.6416 & 1.15151 \\
\hline Valid N (listwise) & 132 & & & & \\
\hline
\end{tabular}

The above descriptive statistics in Table 6 aim to help identify ranges between the data to be able to gain better understanding of the data itself and identify outliers that may be affecting certain results. Given these statistics it is evident that for each variable the mean is slightly above neutral (4) response. This data may be considered over slightly skewed toward the "Agree" response. Outliers are not observed. 
Table 7. Group Statistics by Gender

\begin{tabular}{|l|l|r|r|r|r|}
\hline & Gender & N & Mean & Std. Deviation & Std. Error Mean \\
\hline \multirow{2}{*}{ Trust } & Female & 63 & 5.0556 & .85483 & .10770 \\
\cline { 2 - 6 } & Male & 68 & 4.6471 & .86088 & .10440 \\
\hline Social Influence & Female & 63 & 4.8571 & 1.14803 & .14464 \\
\cline { 2 - 6 } & Male & 68 & 4.4314 & 1.23527 & .14980 \\
\hline Customer Attitude & Female & 64 & 4.9187 & .87048 & .10881 \\
\cline { 2 - 6 } & Male & 68 & 4.6294 & .98117 & .11898 \\
\hline Peer Reputation & Female & 64 & 4.4156 & .90873 & .11359 \\
\cline { 2 - 6 } & Male & 68 & 4.1412 & .98227 & .11912 \\
\hline \multirow{2}{*}{ Business Reputation } & Female & 64 & 5.0052 & .69893 & .08737 \\
\cline { 2 - 6 } & Male & 68 & 4.4363 & .98455 & .11939 \\
\hline Transaction Security & Female & 63 & 4.8995 & 1.01888 & .12837 \\
\cline { 2 - 6 } & Male & 68 & 4.4314 & 1.22989 & .14915 \\
\hline
\end{tabular}

Table 7 reports group means and standard deviation of each variable in terms of gender. The table shows differences between two group means. Such group mean differences will be tested using the t-test models.

Table 8. T-Test Results by Gender

\begin{tabular}{|l|r|r|r|r|r|}
\hline & \multicolumn{1}{c|}{$\mathbf{t}$} & \multicolumn{1}{c|}{$\mathbf{d f}$} & $\begin{array}{c}\text { p-value } \\
\text { (2-tailed) }\end{array}$ & $\begin{array}{c}\text { Mean } \\
\text { Difference }\end{array}$ & $\begin{array}{l}\text { Std. Error } \\
\text { Difference }\end{array}$ \\
\hline Trust* & 2.723 & 129 & .007 & .40850 & .15003 \\
\hline Social Influence* & 2.039 & 129 & .043 & .42577 & .20882 \\
\hline Customer Attitude* & 1.788 & 130 & .076 & .28934 & .16182 \\
\hline Peer Reputation* & 1.663 & 130 & .099 & .27445 & .16499 \\
\hline Business Reputation* & 3.807 & 130 & .000 & .56893 & .14944 \\
\hline Transaction Security* & 2.362 & 129 & .020 & .46810 & .19819 \\
\hline
\end{tabular}

*Equal variances assumed

The t-test in Table 8 which compares Gender to all variables tested, indicates that Trust, Social Influence, Business Reputation and Transaction Security all are statistically significant at an Alpha of 0.05. The highest significance is with Business Reputation with a p-value of 0.000 . Then would be Trust with a p-value of 0.007 and Transaction Security with p-value of 0.02. The last of these is Social Influence with a P-Value of 0.043. In other words there is a 19 out of 20 chance that gender has a significant impact on these four variables. It is also apparent that there is marginal significance between Gender and Customer Attitude (p-value 0.076) and Peer Reputation (p-value 0.099) at an Alpha of 0.10. This means that gender will affect Customer Attitude and Peer Reputation 9 out of 10 times.

Table 9. ANOVA Model Results by Education

\begin{tabular}{|l|c|r|}
\hline & F & p-value \\
\hline Social Influence & $1.118(7,125)$ & .356 \\
\hline Customer Attitude & $2.678(7,126)$ & .013 \\
\hline Peer Reputation & $1.568(7,126)$ & .151 \\
\hline Business Reputation & $2.641(7,126)$ & .014 \\
\hline Transaction Security & $2.068(7,125)$ & .052 \\
\hline Trust & $1.599(7,125)$ & .142 \\
\hline
\end{tabular}

The authors used Education as a demographic to observe its impact on each of the variables used. Table 9 reports ANOVA model results by education. There were a total of eight groups used (see page 2 of questionnaire for complete list). There is statistically significant at an Alpha of 0.05 with Customer Attitudes and Business Reputation with pvalues of 0.013 and 0.014 respectively. It is also marginally significant at an Alpha of 0.10 with Transaction Security with a p-value of 0.052 . 
Table 10. ANOVA Model Results by Income

\begin{tabular}{|l|r|r|}
\hline & \multicolumn{1}{|c|}{ F } & p-value \\
\hline Social Influence & $1.148(5,127)$ & .339 \\
\hline Customer Attitude & $1.410(5,128)$ & .225 \\
\hline Peer Reputation & $.735(5,128)$ & .599 \\
\hline Business Reputation & $.365(5,128)$ & .872 \\
\hline Transaction Security & $1.236(5,127)$ & .296 \\
\hline Trust & $2.306(5,127)$ & .048 \\
\hline
\end{tabular}

Income as a demographic can help us determine whether the respondents have disposable income to be able to purchase online. Table 10 reports ANOVA model results by income. It is statistically significant on the Trust variable with a p-value of 0.048 .

Table 11. ANOVA Model Results by Age

\begin{tabular}{|l|r|r|}
\hline & F & p-value \\
\hline Social Influence & $.907(5,127)$ & .479 \\
\hline Customer Attitude & $.956(5,128)$ & .448 \\
\hline Peer Reputation & $1.034(5,128)$ & .400 \\
\hline Business Reputation & $.539(5,128)$ & .746 \\
\hline Transaction Security & $1.773(5,127)$ & .123 \\
\hline Trust & $1.715(5,127)$ & .136 \\
\hline
\end{tabular}

The Age demographic was used to determine whether there is certain age factors that might influence any of the variables. Table 11 reports ANOVA model results by age. However, to the surprise it is not a significant factor affecting any of the variables.

Table 12. Pearson Correlations

\begin{tabular}{|c|c|c|c|c|c|c|}
\hline & $\mathbf{Y}$ & $\mathrm{X} 1$ & $\mathrm{X2}$ & X3 & $\mathrm{X} 4$ & X5 \\
\hline Trust (Y) & 1 & & & & & \\
\hline Social Influence (X1) & $.554 * *$ & 1 & & & & \\
\hline Customer Attitudes (X2) & $.361 * *$ & $.609 * *$ & 1 & & & \\
\hline Peer Reputation (X3) & $.683 * *$ & $.770 * *$ & $.629 * *$ & 1 & & \\
\hline Business Reputation (X4) & $.448 * *$ & $.551^{* *}$ & $.446^{* *}$ & $.618^{* *}$ & 1 & \\
\hline Transaction Security (X5) & $.555 * *$ & $.497 * *$ & $.483 * *$ & $.656^{* *}$ & $.535^{* *}$ & 1 \\
\hline
\end{tabular}

The Pearson Correlation in Table 12 shows that all variables (IVs) are positively correlated with Trust (DV) and are all significant at an Alpha of 0.01 .

Table 13. Full Regression Model

\begin{tabular}{|c|c|c|c|c|}
\hline \multicolumn{5}{|c|}{$\begin{array}{l}\text { Dependent Variable }=\text { Trust }(\mathrm{Y}) \\
\text { Adjusted } \mathrm{R}^{2}=0.485 \\
\mathrm{~F}(5,126)=25.625^{* * *}\end{array}$} \\
\hline Predictors & B & Beta & $\mathbf{t}$ & p-value \\
\hline Constant & 2.131 & & 6.235 & 0.000 \\
\hline X1-Social Influence & 0.105 & 0.140 & 1.382 & 0.169 \\
\hline X2-Customer Attitude & -0.153 & -0.164 & -1.937 & 0.055 \\
\hline X3-Peer Reputation & 0.499 & 0.533 & $4.519 * * *$ & 0.000 \\
\hline X4-Business Reputation & 0.011 & 0.011 & 0.138 & 0.891 \\
\hline X5-Transaction Security & 0.163 & 0.214 & $2.519 *$ & 0.013 \\
\hline
\end{tabular}




\section{Issues in Information Systems \\ Volume 18, Issue 4, pp. 70-90, 2017}

Table 13 shows that the full regression model is statistically significant with an Adjusted R-Square of 0.485 and a pvalue of 0.000 . Peer Reputation and Transaction Security are statistically significant at an Alpha of 0.05 with p-values of 0.000 and 0.013 respectively. Customer Attitude is also Moderately Significant with a p-value of 0.055 . The authors can tell that there is a multicollinearity issue with Customer Attitudes where it shows a negative relationship to Trust which is contrary to that of what the positive relationship showed by the Pearson Correlation.

Table 14. Reduced Regression Model - Female Only

\begin{tabular}{|c|c|c|c|c|}
\hline \multicolumn{5}{|c|}{$\begin{array}{l}\text { Dependent Variable }=\text { Trust }(\mathrm{Y}) \\
\text { Adjusted } \mathrm{R}^{2}=0.518 \\
\mathrm{~F}(5,56)=14.135^{* * *}\end{array}$} \\
\hline Predictors & $\mathbf{B}$ & Beta & $\mathbf{t}$ & p-value \\
\hline Constant & 2.891 & & 4.152 & 0.000 \\
\hline X1-Social Influence & 0.228 & 0.280 & $2.051 *$ & 0.045 \\
\hline X2-Customer Attitude & -0.317 & -0.326 & $-3.091 * *$ & 0.003 \\
\hline X3-Peer Reputation & 0.618 & 0.633 & $4.436^{* * *}$ & 0.000 \\
\hline X4-Business Reputation & -0.060 & -0.048 & -0.458 & 0.649 \\
\hline X5-Transaction Security & 0.033 & 0.039 & 0.371 & 0.712 \\
\hline
\end{tabular}

The model has been reduced to encompass only the Female responders and Table 14 shows that the Adjusted RSquared increased to 0.518 while keeping the statistically significant $p$-value of 0.000 . Social influence, Customer Attitude and Peer Reputation are all statistically significant at an Alpha of 0.05. Multicollinearity issues have also been identified with this model attributed to Customer Attitude and Business Reputation as they have a negative effect on Trust with is contrary to the Pearson Correlation.

Table 15. Reduced Regression Model - Male Only

\begin{tabular}{|c|c|c|c|c|}
\hline \multicolumn{5}{|c|}{$\begin{array}{l}\text { Dependent Variable }=\text { Trust }(\mathrm{Y}) \\
\text { Adjusted } \mathrm{R}^{2}=0.443 \\
\mathrm{~F}(5,62)=11.644^{* * *}\end{array}$} \\
\hline Predictors & B & Beta & $\mathbf{t}$ & p-value \\
\hline Constant & 2.102 & & 5.050 & 0.000 \\
\hline X1-Social Influence & 0.018 & 0.025 & 0.169 & 0.866 \\
\hline X2-Customer Attitude & 0.019 & 0.022 & 0.145 & 0.885 \\
\hline X3-Peer Reputation & 0.360 & 0.411 & $2.039 *$ & 0.046 \\
\hline X4-Business Reputation & -0.027 & -0.031 & -0.237 & 0.813 \\
\hline X5-Transaction Security & 0.228 & 0.325 & $2.358^{*}$ & 0.022 \\
\hline
\end{tabular}

Table 15 reports reduced regression model-male only. The Male only model is statistically significant. However, its Adjusted R-Square of 0.443 is not as strong as in the combined model. Peer Reputation and Transaction Security are the significant variables at an Alpha of 0.05. Business Reputation shows a negative relationship with trust and is contradictory to its positive Pearson Correlation relationship raising the issue of multicollinearity. 
Table 16. Trust

\begin{tabular}{|c|c|c|c|c|c|}
\hline & & Frequency & Percent & Valid Percent & Cumulative Percent \\
\hline \multirow[t]{18}{*}{ Valid } & 2.25 & 1 & .7 & .8 & .8 \\
\hline & 2.75 & 3 & 2.2 & 2.3 & 3.0 \\
\hline & 3.00 & 2 & 1.5 & 1.5 & 4.5 \\
\hline & 3.25 & 3 & 2.2 & 2.3 & 6.8 \\
\hline & 3.50 & 3 & 2.2 & 2.3 & 9.0 \\
\hline & 3.75 & 6 & 4.5 & 4.5 & 13.5 \\
\hline & 4.00 & 7 & 5.2 & 5.3 & 18.8 \\
\hline & 4.25 & 7 & 5.2 & 5.3 & 24.1 \\
\hline & 4.50 & 22 & 16.4 & 16.5 & 40.6 \\
\hline & 4.75 & 15 & 11.2 & 11.3 & 51.9 \\
\hline & 5.00 & 10 & 7.5 & 7.5 & 59.4 \\
\hline & 5.25 & 14 & 10.4 & 10.5 & 69.9 \\
\hline & 5.50 & 15 & 11.2 & 11.3 & 81.2 \\
\hline & 5.75 & 9 & 6.7 & 6.8 & 88.0 \\
\hline & 6.00 & 9 & 6.7 & 6.8 & 94.7 \\
\hline & 6.25 & 5 & 3.7 & 3.8 & 98.5 \\
\hline & 6.50 & 2 & 1.5 & 1.5 & 100.0 \\
\hline & Total & 133 & 99.3 & 100.0 & \\
\hline Missing & System & 1 & .7 & & \\
\hline Total & & 134 & 100.0 & & \\
\hline
\end{tabular}

As seen in Table 16, it is evident that lower $25 \%$ of the population falls below the score of 4.25 which is defined as Low Trust and the upper nearly $30 \%$ falls above a score of 5.25 which the authors have defined as High Trust. These values will be used as cut off Scores to crate (0-1) dichotomy variable for a redefined dependent variable (Trust 2) using a Logistic Regression model.

\section{Logistic Regression Model}

Table 17 reports full logistic regression model. It is statistically significant with Chi-square at $63.88(\mathrm{p}<0.001)$. Table 17 also shows 47.653 for -2 Log likelihood, .528 for Cox \& Snell R-Squared, and Nagelkerke R-Square of 0.723.

Table 17. Full Logistic Regression Model

\begin{tabular}{|l|r|r|r|r|}
\hline Trust (Y) & \multicolumn{1}{|c|}{ B } & \multicolumn{1}{c|}{ S.E. } & p-value & \multicolumn{1}{c|}{$\operatorname{Exp(B)}$} \\
\hline X1-Social Influence & .352 & .509 & .489 & 1.422 \\
\hline X2-Customer Attitude & .204 & .517 & .693 & 1.227 \\
\hline X3-Peer Reputation & 2.363 & .832 & .005 & 10.625 \\
\hline X4-Business Reputation & -.176 & .419 & .674 & .838 \\
\hline X5-Transaction Security & .965 & .438 & .028 & 2.624 \\
\hline Constant & -15.628 & 3.989 & .000 & .000 \\
\hline
\end{tabular}

Score $($ Level of Trust $)=-15.628+0.352 \mathrm{X} 1+0.204 \mathrm{X} 2+2.363 \mathrm{X} 3-0.176 \mathrm{X} 4+0.965 \mathrm{X} 5$

$$
\mathrm{p}=\frac{\mathrm{e}^{(-15.628+0.352 \times 1+0.204 \times 2+2.363 \times 3-0.176 \times 4+0.965 \times 5)}}{1+\mathrm{e}^{(-15.628+0.352 \times 1+0.204 \times 2+2.363 \times 3-0.176 \times 4+0.965 \times 5)}}
$$

where $\mathrm{p}=$ the probability of success $($ dependent variable $=1)$ 


\section{Issues in Information Systems}

Volume 18, Issue 4, pp. 70-90, 2017

Table 18. Classification Table

\begin{tabular}{|c|c|c|c|}
\hline \multirow[b]{3}{*}{ Observed } & \multicolumn{3}{|c|}{ Predicted } \\
\hline & \multicolumn{2}{|c|}{ Trust_2 } & Percentage \\
\hline & Low Trust & High Trust & Correct \\
\hline Low Trust & 25 & 6 & 80.6 \\
\hline High Trust & 4 & 50 & 92.6 \\
\hline Overall Percentage & & & 88.2 \\
\hline
\end{tabular}

a. The cut value is .500

This model has successfully predicted $88.2 \%$ of the tested population which is computed by $(25+50) / 85$ in the sample data. as shown in Table 18.

\section{Structural Equation Model}

The structural equation modeling (SEM) analysis was also conducted to test the hypotheses. The IBM AMOS 23 was utilized for the data analysis. However, the SEM analysis can be performed only after adequate model fit is achieved so the validation of measures in this study was first examined by factor analysis, and then some problematic measure items which did not satisfy the minimum threshold were removed. The goodness-of-fit of the model was assessed by several different fit indices such as the normed chi-square, the comparative fit index (CFI), the normed fit index (NFI), and the Tucker-Lewis index (TLI). Through this process, the authors could obtain the adequate model for the SEM analysis which satisfied the desirable thresholds for each goodness-of-fit index, as shown in Tables 19 and 20.

Table 19. Factor Analysis

\begin{tabular}{|c|c|c|c|c|c|c|c|c|c|}
\hline \multirow{2}{*}{ Factor } & \multirow[b]{2}{*}{ Item } & \multicolumn{4}{|c|}{ Initial Estimates } & \multicolumn{4}{|c|}{ Final Estimates } \\
\hline & & Loading $^{\text {a }}$ & S.E. ${ }^{b}$ & C.R. ${ }^{\mathrm{c}}$ & $\mathbf{P}$ & Loading & S.E. & C.R. & $\mathbf{P}$ \\
\hline \multirow{3}{*}{$\begin{array}{c}\text { Social } \\
\text { Influence }\end{array}$} & $\mathrm{Q} 4$ & .625 & $--^{d}$ & - & - & .673 & - & - & - \\
\hline & Q6 & .615 & .204 & 6.162 & $* * *$ & & & & \\
\hline & Q14 & .810 & .162 & 7.602 & $* * *$ & .723 & .132 & 7.728 & $* * *$ \\
\hline \multirow{5}{*}{$\begin{array}{l}\text { Customer } \\
\text { Attitudes }\end{array}$} & Q1 & .615 & - & - & - & .625 & - & - & - \\
\hline & Q10 & .189 & .131 & 2.027 & .043 & & & & \\
\hline & Q17 & .572 & .134 & 5.606 & $* * *$ & .613 & .136 & 5.832 & $* * *$ \\
\hline & Q19 & .391 & .155 & 4.044 & $* * *$ & & & & \\
\hline & Q24 & .395 & .115 & 4.073 & $* * *$ & & & & \\
\hline \multirow{5}{*}{$\begin{array}{c}\text { Peer } \\
\text { Reputation }\end{array}$} & Q2 & .602 & - & - & - & & & & \\
\hline & $\mathrm{Q} 8$ & .624 & .142 & 6.447 & $* * *$ & & & & \\
\hline & Q11 & .477 & .153 & 5.185 & $* * *$ & & & & \\
\hline & Q16 & .674 & .145 & 6.840 & $* * *$ & .714 & .117 & 8.448 & $* * *$ \\
\hline & Q23 & .710 & .146 & 7.104 & $* * *$ & .726 & - & - & - \\
\hline \multirow{3}{*}{$\begin{array}{l}\text { Business } \\
\text { Reputation }\end{array}$} & Q5 & .330 & - & - & - & .424 & - & - & - \\
\hline & Q13 & .580 & .552 & 4.024 & $* * *$ & & & & \\
\hline & Q21 & .320 & .318 & 3.136 & .002 & .692 & .472 & 3.543 & $* * *$ \\
\hline \multirow{3}{*}{$\begin{array}{c}\text { Transaction } \\
\text { Security }\end{array}$} & Q9 & .733 & - & - & - & .664 & - & - & - \\
\hline & Q15 & .377 & .144 & 4.007 & $* * *$ & & & & \\
\hline & Q22 & .836 & .123 & 8.396 & $* * *$ & .952 & .185 & 6.991 & $* * *$ \\
\hline \multirow{4}{*}{ Trust } & Q3 & .365 & - & - & - & & & & \\
\hline & Q7 & .068 & .224 & .711 & .477 & & & & \\
\hline & Q12 & .775 & .572 & 3.852 & $* * *$ & .791 & - & - & - \\
\hline & Q20 & .674 & .525 & 3.738 & $* * *$ & .713 & .126 & 7.330 & $* * *$ \\
\hline
\end{tabular}

*** $p<0.001 ;{ }^{\mathrm{a}}$ Standardized factor loading; ${ }^{\mathrm{b}}$ Standard error; ${ }^{\mathrm{c}}$ Critical ratio; ${ }^{\mathrm{d}}$ Not estimated when loading set to fixed value (i.e., 1.000). 
Table 20. Goodness-of-fit of the Model

\begin{tabular}{|lr|c|c|}
\hline \multicolumn{1}{|c|}{ Fit Index } & $\begin{array}{c}\text { Desirable } \\
\text { Threshold }\end{array}$ & Initial Model Fit Statistics & Final Model Fit Statistic \\
\hline Chi-square $\left(\boldsymbol{X}^{\mathbf{2}}\right)$ & 520.257 & 87.392 \\
\hline Degree of Freedom (d.f.) & 215 & 39 \\
\hline $\boldsymbol{X}^{2} /$ d.f. & $<3.00$ & 2.420 & 2.241 \\
\hline $\mathbf{C F I}^{\mathbf{a}}$ & $>0.90$ & .735 & .918 \\
\hline $\mathbf{N F I}^{\mathbf{b}}$ & $>0.50$ & .635 & .870 \\
\hline $\mathbf{T L I}^{\mathbf{c}}$ & close to 1.00 & .659 & .837 \\
\hline
\end{tabular}

${ }^{\mathrm{a}}$ Comparative fit index; ${ }^{\mathrm{b}}$ Normed fit index; ${ }^{\mathrm{c}}$ Tucker-Lewis index.

Figure 2 depicts the SEM test results with the standardized path coefficient, significance level, and $t$-value. As demonstrated in the Figure, the path coefficient between social influence and trust is positively significant $(B=.221$, $p=.029, \mathrm{t}=2.178)$. Further, the path coefficient between peer reputation and trust is significantly positive ( $\beta=.749$, $p<.001, t=5.290$ ). However, the other paths did not indicate any positive relationship between each factor and trust.

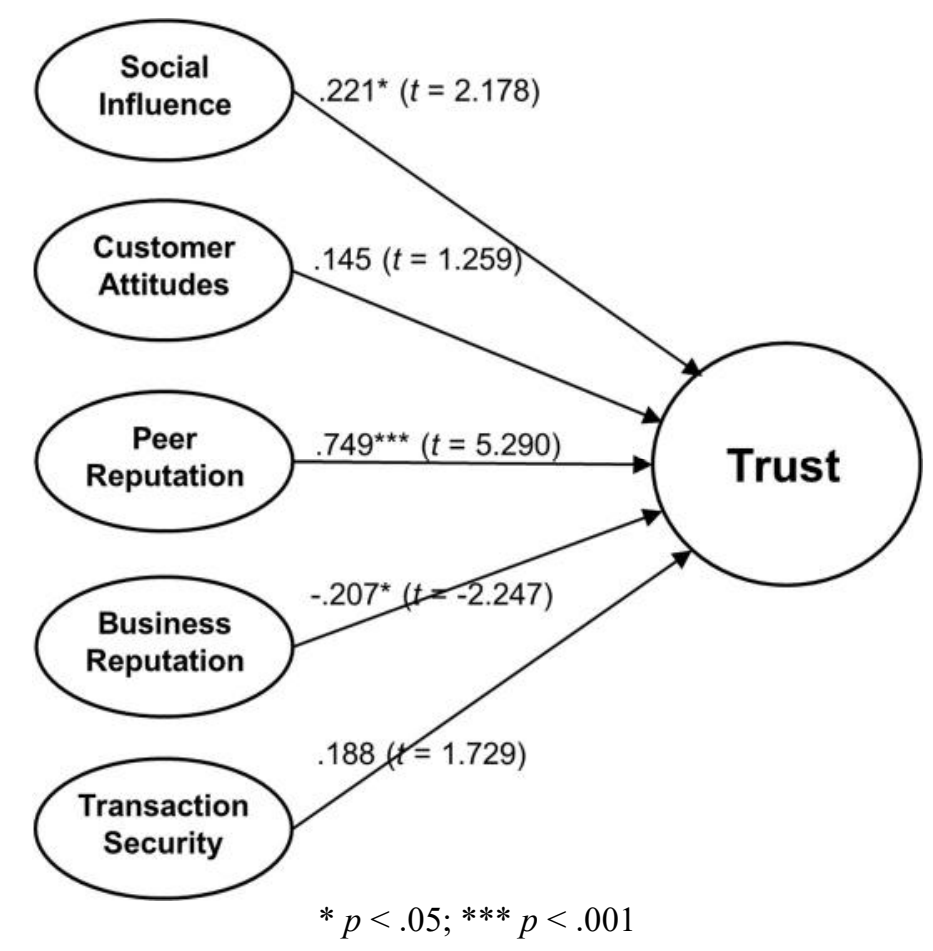

Figure 2. SEM Test Results

\section{DISCUSSION}

\section{Trust}

Gender is found to be significantly related to trust given the t-test, however, there is no literature to support this finding. The ANOVA model by trust shows that income is statistically significance on the trust variable, which is also not supported in the literature. A Pearson correlation model shows that social influence, customer attitude, peer reputation, business reputation, and transaction security are all positively correlated with trust ( $>0.01$ level), or as these variables increase so does the level of trust to make s-commerce purchases, a finding consistent with the literature 
review (Hajli, 2014; Beyari, \& Abareshi, 2016; Shin, 2013; Shanmugam, 2016; Fairweather, 2004; Chen, 2015). The full regression model is statistically significant but only for peer reputation and transaction security (at the 0.05 level) and customer attitude as moderately significant. Mixed results is further witnessed when examining the female only and male only regression models, where each of these models shows statistical significance with the female model showing a stronger significance in which women are statistically significantly more likely than men to use social influence, customer attitudes, peer reputation, business reputation and transaction security to gain greater trust in scommerce purchase decisions. While the logistic regression model is significant and successfully predicts $88.2 \%$ of the sample population, the overall results for the trust variable are mixed.

Hypothesis 1: Social influence is significantly related to trust in s-commerce.

There was no literature to support the finding that gender is significantly related to social influence, however, through the use of the t-test the authors found that a person's gender does play a statistically significant role in a person relying on social influences (customer testimonials, ratings, opinions and experiences) in determining to purchase online. There was no statistical significance in the ANOVAs between Social Influence and a person's education or income when making purchase decisions. The Pearson correlation model shows that social influence is positively related to trust ( $\mathrm{p}>0.01$ level), or as social influence factors increase, the level of consumer trust increases, consistent with the current research (Hajli, 2014; Beyari, \& Abareshi, 2016; Shin, 2013; Shanmugam, 2016; Fairweather, 2004; Chen, 2015). When considering the full regression model, social influence is not statistically significant. Results show that there is more of a data fit when considering only females rather than only males, indicating that women are more statistically likely to use social influence factors when making purchases over social commerce than men. No statistical significance is found when considering all of the independent variables together. While the logistic regression model successfully predicts $88.2 \%$ of the sample population, the authors must conclude that hypothesis 1 cannot be accepted due to mixed results.

\section{Hypothesis 2: Customer attitudes, biases, and past experiences are significantly related to trust in s- commerce.}

A statistical significance was found in the ANOVA test between a person's education and customer attitudes, biases and past experiences impacting the decision to purchase over the s-commerce platform. However, there was no support in the literature review for education level and customer attitudes. A pearson correlation model shows that customer attitude is positively related to trust ( $p>0.01$ level), indicating that as perceived attitudes and biases are positively impacted by the sharing of information, reviews, recommendations, ratings, feedback and word-of-mouth, trust will also increase, as supported by the literature review (Hsiao, 2010; Beyari \& Abareshi, 2016; Shin, 2013; Bai, Yao, \& Dou, 2015; Talat, Azar, \& Yousaf, 2013; Hajli, 2013; Shanmugam, Sun, Amindi, Khani, \&, Khani, 2016; Mutz, 2009; Craig, 2004; Chen, 2003; Han \& Windsor, 2011). While the literature review supports the finding that customer attitudes is significantly related to trust and intention to buy, it is important to mention that Lee et al. (2011) found the opposite. If trust is low, there is no significant difference in consumers' purchase intentions irrespective of advertisement. However, when trust level is high, information is perceived to be meaningful and positively influences a consumer's decision and purchase intent. When considering the full regression model, customer attitudes is moderately statistically significant $(\mathrm{p}<0.05$ level $)$ and there is an even stronger data fit when considering females only, while the male model is not as strong as the combined model. This finding indicates that women are more statistically likely to use customer attitudes and support factors in determining their level of trust to make purchases over social commerce, however men to are not statistically likely to use customer attitudes to make online s-commerce purchases. The logistic regression does not show statistical significance. Given these mixed results the authors conclude that hypothesis 2 is not fully supported and the authors deem the findings inconclusive.

\section{Hypothesis 3: Reputation of business is significantly related to trust in s-commerce.}

This study shows mixed results that the Business Reputation is related to trust in S-Commerce. In the t-test results, gender does play a role and is statistically significant when it comes to the reputation of a business in s-commerce. As far as ANOVAs for income and education levels are concerned, the authors can conclude that education is statistically significant when it comes to Business Reputation. But on the other hand, income is not significant. The Pearson Correlation Model shows that the Business Reputation is positively related to trust. This is consistent with the studies of Beyari and Abareshi, Braynov \& Sandholm, Han and Winsor (2011). When it comes to the regression model the authors see that overall it is not statistically significant. When looking at the female and male model the results stayed the same. The indication here is that both males and females view that the reputation of business is not significant 
when it comes to s-commerce. The logistics regression model results show that Business Reputation is not a significant factor so the authors accept the null hypothesis that Business Reputation is not a significant factor in determining the level of Trust within s-commerce given the inconclusive results. Based on the findings, the authors cannot support hypothesis 3 due to mixed results.

\section{Hypothesis 4: Reputation of peers is significantly related to trust in s-commerce.}

The study supports the finding that the Peer Reputation significantly relates to trust in s-commerce as shown/attributed by the following studies of Hsiano (2010), Beyari and Abareshi (2016), Han and Windsor (2011) As far as the gender $\mathrm{t}$-test is concerned, there appears to be a marginal correlation/relation to trust and s-commerce. This is when comparing to an alpha level of 0.10 . There is a 1 in 10 chance that gender will have an impact on Peer Reputation in s-commerce. The ANOVA test show that education level and income are not statistically significant when it comes to Peer Reputation. The Pearson Correlation model shows that the reputation of peers is significantly, positively related to trust at a 0.01 level. When concerning the regression model, the authors see that the overall model shows a statistical significance for Peer Reputation. When comparing both the male and female models, the authors see that both genders viewed the reputation of peers are statistically significant. The female model is a slightly stronger and as a result is the better fit model. The logistic regression model also shows statistical significance. Based on the finding and of the support of additional research articles, the authors can support hypothesis 4 .

\section{Hypothesis 5: Transaction security is significantly related to trust in s-commerce.}

Evidence of this study does support the finding that Transition Security is significantly related to trust in s-commerce and supports the finding of Beyari and Abareshi (2016), Hsiano (2010) and Lee (2015). The t-test shows that gender does play a role and or is statistically significant when it comes to transactional security in s-commerce. In the ANOVA test, educational level is marginally significant when it comes to transactional security. On the other hand, income does not show a statistical significance on transactional security. The Pearson Correlation model shows that transactional security is significantly related to trust in the s-commerce. The authors have also observed significance in the overall full regression model, however the Female reduced model fails to display statistical significance. On the other hand, the Male reduced model shows transactional security as being statistically significant. The logistic regression model also supports this finding. This is a very interesting and the authors feel that the studies and the findings for this particular hypothesis support the alternative hypothesis. Based on the findings, the authors cannot support hypothesis 5 due to mixed results.

\section{Managerial Implications}

This study was performed to get a more complete understanding of the factors that influence Trust as it relates to scommerce. Previous studies have identified trust as a major factor that influences s-commerce, by identifying variables that impact Trust the authors can help e/s-commerce businesses build better relationships with their consumers which would ultimately lead to greater online sales. Managers charged with creating a good social media impression are doing so to increase the chance of purchase. Social media managers need to focus directly on how they are perceived by their actual customers, who in turn become credible peer reviewers for other potential customers on social networks. Other managerial considerations are the security of their websites as well as their customer's private information.

\section{CONCLUSION}

The results show mixed results when it comes to Social Influence, Customer Attitudes and Business Reputation. Given the Pearson Correlations all factors are statistically significant with regards to their impact on Trust. However the other models clearly point to Transaction Security and Peer Reputation as being very important in determining the level of Trust in s-commerce. The study has also shown that there is some differences in factors that influence trust between the genders. Women tend to rely on Social Influence, Customer Attitude and Peer Reputation to determine their trust level. Men also rely on Peer Reputation, however they are impacted by Transaction Security unlike Women. All models showed statistical significance overall, which means that the study was overall successful in helping us determine what factors affect Trust in s-commerce. The authors conclude that Transactional Security and Peer Reputation are the most important factors influencing Trust in s-commerce. Contrary to the research the authors have 


\section{Issues in Information Systems \\ Volume 18, Issue 4, pp. 70-90, 2017}

found that that Social Influence, Customer Attitudes and Business Reputation showed mixed results and did not prove to be good predictors of Trust. The authors deem these three results as inconclusive at this time.

Although the study had mixed results, the authors think that it contributes to other studies that use Trust as a factor in the context of e/s-commerce. There are many limitations the authors have been faced with and the authors recommend the following improvements for future studies. First, the data sample was limited with only 134 responses gathered in a relatively small geographic area of the New England, USA. The authors would recommend to increase the sample size and to obtain data from a larger geographic area. Second, the study was limited to five variables, but the authors think it would have been more impactful if a greater number of variables were introduced like time, customer service, third party assurance (Better Business Bureau approved), and website quality. Third, although the study is in essence a general study of the population, the authors think it could be more beneficial if focused on a particular industry within the s-commerce scope such as electronics, consumer goods (i.e. food/apparel) or other media. Lastly, the authors only used a few analytical models to get an understanding of the data the authors gathered, however other best-fit and advanced models such as Structural Equation Model or Survival Model can be used to expand the understanding of Trust within e/s-commerce.

This research contributes to literature about s-commerce from the perspective of one factor. The authors focused on Trust, but other factors also impact e/s-commerce and through the findings the authors have provided a way to further develop a more focused approach in analyzing other significant variables. The study helps business zero in on the variables that are most important when attempting to develop Trust in s-commerce which will help them expand their business worldwide.

\section{REFERENCES}

Bai, Y., Yao, Z., \& Dou, Y.-F. (2015). Effect of Social Commerce Factors on User Purchase Behavior: An Empirical Investigation From Renren.com. International Journal of Information Management, 35(5), 538550.

Beyari, H., \& Abareshi, A. (2016). The Conceptual Framework of the Factors Influencing Consumer Satisfaction in Social Commerce. The Journal of Developing Areas, 50(6), 365-376.

Yu, B., \& Singh, M. P. (2002). Distributed Reputation Management for Electronic Commerce. Computational Intelligence, 18(4), 535-549.

Braynov, S., \& Sandholm, T. (2002). Contracting with Uncertain Level of Trust. Computational Intelligence, 18(4), 501-514.

Chen, C. (2003). An Investigation of Significant Factors Affecting Consumer Trust in e -Commerce, University of Nevada, Las Vegas, Ann Arbor. ProQuest Dissertations Publishing. Retrieved from http://0search.proquest.com.www.consuls.org/docview/305268808?accountid=9970.

Chen, J., \&. Shen, X. (2015). Consumers' decisions in social commerce context: An empirical investigation Decision Support Systems, 79(2015), 55-64. Retrieved from http://0search.proquest.com.www.consuls.org/docview/1733937948?accountid=9970

Chen, Y. (2006). Factors that affect online consumer trust in Taiwan, Lynn University, Ann Arbor. ProQuest Dissertations \& Theses Global. Retrieved from http://0search.proquest.com.www.consuls.org/docview/304909757?accountid $=9970$

Craig, V. S. (2004). Factors influencing the adoption of web-based shopping: The impact of trust. Database for Advances in Information Systems, 35(2), 32-49. Retrieved from http://0search.proquest.com.www.consuls.org/docview/196633014?accountid=9970 


\section{Issues in Information Systems}

Volume 18, Issue 4, pp. 70-90, 2017

Fairweather, K. F. (2004). The impact of e -commerce activities on trust and commitment, Nova Southeastern University, Ann Arbor. ProQuest Dissertations \& Theses Global. Retreived from http://0search.proquest.com.www.consuls.org/docview/305043829?accountid=9970

Hajli, M. (2013). A research framework for social commerce adoption. Information Management \& Computer Security, 21(3), 144-154. Retrieved from http://0-dx.doi.org.www.consuls.org/10.1108/IMCS-04-20120024

Hajli, M. N. (2014). Social Commerce for Innovation. International Journal of Innovation Management, 18(4), 124. Retrieved from http://0-search.proquest.com.www.consuls.org/docview/1546003320?accountid=9970

Han, B., \&. Windsor, J. (2011). User's willingness to pay on social network sites. The Journal of Computer Information Systems, 51(4), 31-40. Retrieved from http://0search.proquest.com.www.consuls.org/docview/884811181 ?accountid $=9970$

Hwang, I., Lee, B., \& Kim, K. (2014). Information Asymmetry, Social Networking Site Word of Mouth, and Mobility Effects on Social Commerce in Korea. CyberPsychology, Behavior \& Social Networking, 17(2), $117-124$.

Kim, S., \& Park, H. (2013). Effects of various characteristics of social commerce (s-commerce) on consumers' trust and trust performance. International Journal of Information Management, 33(2), 318-332.

Hsiao, K., Lin, J., Wang, X., Lu, H., \& Yu, H. (2010). Antecedents and consequences of trust in online product recommendations. Online Information Review, 34(6), 935-953. Retrieved from http://0-

dx.doi.org.www.consuls.org/10.1108/14684521011099414

Lee, J. Y. (Winter 2015). Trust and Social Commerce. University of Pittsburg Law Review, 77(2), 137-181.

Lee, J., Park, D.-H., \& Han, I. (2011). The Different Effects of Online Consumer Reviews on Consumers' Purchase Intentions Depending on Trust in Online Shopping Malls: An Advertising Perspective. Internet Research, 21(2), 187-206.

Lee, Y.-K., Kim, S. Y., Chung, N., \& Lee, J.-W. (2016). When Social Media Met Commerce: A Model of Perceived Customer Value in Group-Buying. Journal of Services Marketing, 30(4), 398-410.

Liang, T.-P., Ho, Y.-T., Li, Y.-W., \& Turban, E. (2014). What Drives Social Commerce: The Role of Social Support and Relationship Quality. International Journal of Electronic Commerce, 16(2), 69-90.

Mutz, D. (2009). Effects of Internet Commerce On Social Trust. Public Opinion Quarterly, 73(3), 439-461.

Kim, S., \& Park, H. (2013). Effects of Various Characteristics of Social Commerce on Consumers Trust and Trust Performance. International Journal of Information Management, 33(2), 318-332.

Rushton, A., Croucher, P., \& Baker, P. (2017). The Handbook of Logistics and Management. London, United Kingdom: Kogan Page Publishers

Shanmugam, M., Sun, S., Amindi, A., Khani, F., \& Khani, F. (2016). The Application of Social Commerce Construct. International Jurnal of Information Management, 36(3), 425-432.

Shen, J., \& Eder, L. (2011). An examination of factors associated with user acceptance of social shopping websites. International Journal of Technology and Human Interaction, 7(1), 19-36. 


\section{Issues in Information Systems}

Volume 18, Issue 4, pp. 70-90, 2017

Shi, S. \& Chow, W. (2015). Trust development and transfer in social commerce: prior experience as moderator. Industrial Management \& Data Systems, 115(7), 1182-1203. Retrieved from http://0dx.doi.org.www.consuls.org/10.1108/IMDS-01-2015-0019

Shin, D.-H. (2013). User Experience in Social Commerce: In Friends We Trust. Behaviour \& Information Technology, 32(1), 52-67.

Talat, A., Azar, S., \& Yousaf, M. W. (2013). Investigating Social Commerce as an Alternate Model for Online Commerce in Developing Countries: A Case of Pakistani Economy. Pakistan Journal of Commerce and Social Services, 7(1), 223-242.

Van Slyke, C., Belanger, F., \& Comunale, C. (2004). Factors influencing the adoption of web-based shopping: the impact of trust. ACM SIGMIS, 35(2), 32-49. Retrieved from 10.1145/545151.545155 


\section{APPENDIX \\ QUESTIONNAIRE}

This survey is a business class project at Central Connecticut State University. The purpose of this research is to learn about social commerce ( 5 -commerce), a term which describes e-commerce over social networks such as Facebook, Twitter, and others. Your response will be kept anonymous. This survey will take about 3 to 4 minutes. The results vill be used solely for educational and academic purpose. Your participation in this survey is greatly appreciated.

\begin{tabular}{|c|c|c|}
\hline \multicolumn{3}{|c|}{$\begin{array}{l}\text { Please answer as honestly as possible for the following questions by circling a single number, where " } 7 \text { " } \\
\text { represents strongly agree while " } 1 \text { " represents strongly disagree. }\end{array}$} \\
\hline 1 & Customer Attitudes & $\begin{array}{l}\text { I tend to benefit from reviewing feedback on social networks before making an } \\
\text { online purchase. }\end{array}$ \\
\hline 2 & Peer Reputation & I feel that recommendations from my peers are generally reliable \\
\hline 3 & Trust & I trust online shopping websites like Amazon and eBay. \\
\hline 4 & Social Influence & Customer testimonials usually impact my decision to make a purchase. \\
\hline 5 & Business Reputotion & $\begin{array}{l}\text { When shopping online, I believe that the company is acting in the best interest of } \\
\text { others. }\end{array}$ \\
\hline 6 & Social Influence & I often seek opinions of online shoppers who face similar problems as I do. \\
\hline 7 & Trust & I tend to use a credit/debit card to purchase products and services online. \\
\hline 8 & Peer Reputation & $\begin{array}{l}\text { l expect that the advice given by the s-commerce community is their best } \\
\text { judgement. }\end{array}$ \\
\hline 9 & Social Influence & $\begin{array}{l}\text { S-commerce websites give me an impression that they keep my privacy information } \\
\text { safe. }\end{array}$ \\
\hline 10 & Customer Attitudes & $\begin{array}{l}\text { I typically will not make an online purchase if I have had a bad experience with the } \\
\text { company (regardless of strong peer reviews). }\end{array}$ \\
\hline 11 & Peer Reputation & I get the emotional help and support I need from the s-commerce community. \\
\hline 12 & Trust & I trust the product/service information displayed on social networks. \\
\hline 13 & Business Reputotion & I use s-commerce services for brands that I am loyal to. \\
\hline 14 & Social Influence & I tend to trust the ratings on s-commerce websites. \\
\hline 15 & Transoction Security & $\begin{array}{l}\text { Using a third party payer website (such as PayPal) makes s-commerce transactions } \\
\text { safe. }\end{array}$ \\
\hline 16 & Peer Reputation & $\begin{array}{l}\text { When shopping online, I believe that the s-commerce community is acting in the } \\
\text { best interest of others. }\end{array}$ \\
\hline 17 & Customer Attitude & $\begin{array}{l}\text { The social aspect of online shopping enables me to discover new products and get } \\
\text { shopping idea more quickly. }\end{array}$ \\
\hline 18 & Social Influence & $\begin{array}{l}\text { I often like to talk with other online shoppers about mutual opinions and } \\
\text { experiences. }\end{array}$ \\
\hline 19 & Customer Attitude & $\begin{array}{l}\text { Without positive s-commerce community feedback on a product or service I will not } \\
\text { make a purchase. }\end{array}$ \\
\hline 20 & Trust & I trust social networking websites. \\
\hline 21 & Business Reputotion & $\begin{array}{l}\text { The general reputation of a company impacts my decision to make an online } \\
\text { purchase from their website. }\end{array}$ \\
\hline 22 & Transoction Security & I believe s-commerce websites have my information safety in mind. \\
\hline 23 & Peer Reputation & $\begin{array}{l}\text { I generally trust the feedback about a company from those in the s-commerce } \\
\text { community. }\end{array}$ \\
\hline 24 & Customer Attitudes & My personal values impact how much trust I have in s-commerce. \\
\hline
\end{tabular}


Please circle the number with the appropriate answer for each item below.

25. How often do you make online purchases per month?

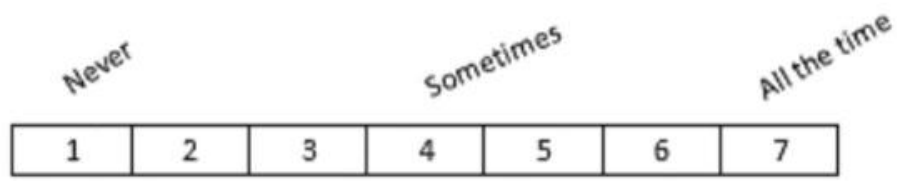

Please check the box with the appropriate answer for each item below.

26. Which one best describes your education background?
[ ] Some high school
[ ] High school diploma
[ ] spme college
[ ] 2 year college degree
[ ] 4 year college degree
[ ] Master degree
[ ] Doctoral degree
[ ] Prefer not to respond

27 . What range best describes your yearly income?
[ ] $<\$ 25,000$
[ ] $\$ 25,000-\$ 40,000$
[ ] $\$ 41,000-\$ 60,000$
[ $\$ 61,000-\$ 80,000$
[ ] $\$ 81,000+$
[ ] Prefer not to respond

28. Which age category do you fall under?
[ ] 18-24
[ ] 25-34
[ ] $35-44$
[ ] $45-54$
[ ] $] 55+$
[ ] Prefer not to respond

29. What is your gender?

[ ]Female [ ] Male [ ] Prefer not to respond 